Article

\title{
Design and Analysis of Novel Low-Cost Linear Vibration Motor for an Electronic Cigarette
}

\author{
Zhi-Xiong Jiang (D), Ki-Hong Park and Sang-Moon Hwang *(1) \\ School of Mechanical Engineering, Pusan National University, Pusan 46241, Korea; \\ jzx20181118@pusan.ac.kr (Z.-X.J.); airnature@pusan.ac.kr (K.-H.P.) \\ * Correspondence: shwang@pusan.ac.kr; Tel.: +82-051-510-3204
}

Received: 20 November 2020; Accepted: 12 December 2020; Published: 14 December 2020

Featured Application: The novel linear vibration motor can be used in an electronic cigarette and in a smartphone or smartwatch to reduce the thickness of devices.

\begin{abstract}
The spring structure design and magnetic circuit optimization were considered to design a novel linear vibration motor with advantages of lower cost and similar motor performance compared to a coin-type vibration motor. A vibration motor is inserted in an electronic cigarette to provide haptic feedback to remind the user that the electronic cigarette is ready to operate. For the new generation of electronic cigarettes, new vibration motors require smaller size, lower cost, and acceptable motor performance. A three-dimensional finite element method has been used to find the coil's magnetic flux density and von Mises stress distribution in the spring. Moreover, the electromagnetic-mechanical coupling method has been employed to find the motor acceleration on a dummy jig. The acceleration of the vibration motor was obtained to verify the analysis results by experiment. The experiment results verified the analysis results of the linear vibration motor. Compared to a coin-type vibration motor, the novel linear vibration motor has $9.09 \%$ and $80.77 \%$ reductions in total thickness and manufacturing cost, and a $40.0 \%$ improvement in acceleration.
\end{abstract}

Keywords: linear vibration motor; electromagnetic-mechanical coupling; finite element method; electronic cigarette

\section{Introduction}

Compared to traditional cigarettes, more and more electronic cigarettes (E-cigarettes) [1] are widely used, which can be useful to quit smoking. They reduce the hazardous effects of some traditional cigarettes and risk of fires, and they keep people away from carcinogens in traditional cigarettes. E-cigarettes do not need to burn but only produce an aerosol by heating the cigarettes. Vibration motors are used to remind the user that E-cigarettes are ready to operate by providing haptic feedback.

Many studies on vibration motors have been completed. A coin-type vibration motor creates a large acceleration in the form of eccentric vibration, but it has a short product life due to wear of the bushing and bearing. Hwang et al. proposed a simpler structure with a longer life span by eliminating small commutation parts [2]. A horizontal linear vibrating actuator was designed by Lee et al. to reduce the thickness of a smartphone and provide better haptic performance compared to a vertical linear vibration actuator. However, the specifications of horizontal linear vibration are $16.5 \mathrm{~mm}$ in length and $15.0 \mathrm{~mm}$ in width, which are too big to apply in E-Cigarettes [3].

A new design of a linear actuator with great magnetic force was proposed by Nam et al. to reduce the response time under given constraints on volume and rated power [4]. Jiang et al. investigated the linear vibration motor used on a liquid crystal display (LCD) display to reduce the magnetic flux leakage by employing mechanical finite element analysis and experimental verification [5]. These vibration 
motors are widely used in smartphones, tablets, and car touch screens. However, few studies have involved a linear vibration motor inside an electronic cigarette due to the size problem, and previous works do not take a dummy jig into consideration in the analysis. The acceleration of linear vibration is measured by specified equipment (a $100 \mathrm{~g}$ dummy jig) with a similar weight to a smartphone or E-cigarette.

This research proposes a novel linear vibration motor with smaller size $(\varnothing 8.0 \times 2.5 \mathrm{~mm})$, higher motor performance at $250 \mathrm{~Hz}$, and lower manufacturing cost due to a reduced number of fabricated parts and complexity of the manufacturing process. First of all, the comparison between coin-type vibration motor and novel linear vibration motor is discussed, including the working principle, advantages, and disadvantages. Secondly, the electrical material properties are introduced to obtain the average flux density on the voice coil considering nonlinear B-H behavior of the yoke and top plate. The mechanical material properties were used to conduct modal analysis and static analysis to obtain the resonance frequency and von Mises stress distribution on the spring, respectively. They were also used to do an electromagnetic-mechanical coupling analysis.

Thirdly, a coin-type vibration sample, a linear vibration motor prototype, and experiment setups are discussed. The analysis results of the prototype have been verified. Based on the analysis methods, novel linear vibration motors have been developed to reduce the resonance frequency and improve the magnetic force by considering a novel spring structure and magnetic circuit optimization. Then, two novel types of linear vibration motors were manufactured to check the acceleration on a dummy jig. Both experimental results match well with the analysis results. The novel type (spring thickness $=0.13 \mathrm{~mm}$ ) shows better acceleration performance than the coin-type vibration motor at a certain frequency range (around $250 \mathrm{~Hz}$ ). Compared to the coin-type vibration motor, the novel linear vibration motor has a $9.09 \%$ reduction in total thickness, an $80.77 \%$ reduction in manufacturing cost, and a $40.0 \%$ improvement in acceleration at $250 \mathrm{~Hz}$.

\section{Model Description}

\subsection{Coin-Type Vibration Motor}

A coin-type vibration motor generally includes a stator assembly in the form of a stationary part and a rotor assembly in the form of a rotary part. The stator assembly has a lower case, an upper case, a shaft, a flexible printed circuit board (FPCB), brushes, and a permanent magnet. The rotor assembly can rotate around the shaft and has a bearing, two voice coils, a weight, a communication circuitry, and a metal commutator. The stator assembly is electrically connected to the rotor assembly via brushes that are fixed at the top surfaces to the lower case and the bottom surfaces of the metal commutator. The full model, half model, and exploded view of the coin-type vibration motor are shown in Figure 1.
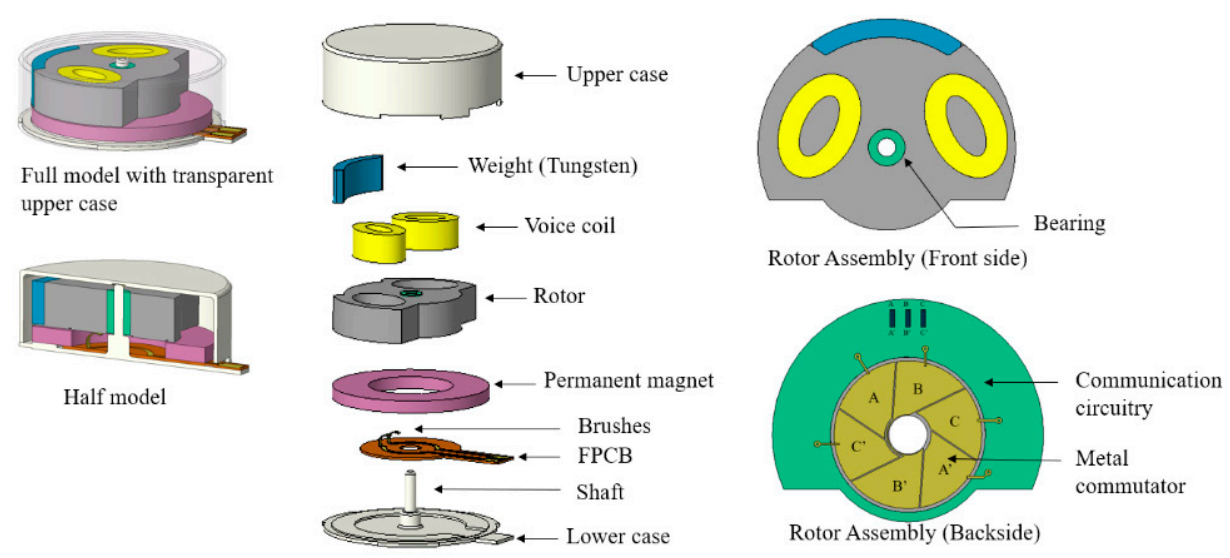

Figure 1. The exploded view and a cross-sectional view of a coin-type vibration motor. 
The coin-type vibration motor generates rotational force to turn a rotary unit with an unbalanced mass, thereby obtaining mechanical vibration. The rotational force is generally produced by supplying voltage to a rotor voice coil through the communication circuitry by contacts of the brushes and metal commutator. Unfortunately, brushes passing through a gap between segments of the metal commutator create mechanical friction and electric sparks. These phenomena shorten the lifetime of the vibration motor and cause unstable haptic performance.

\subsection{Linear Vibration Motor}

Generally speaking, a linear vibration motor includes a stator assembly and a vibrator assembly. The stator assembly has a lower case, an upper case, an FPCB, and a voice coil. The vibrator assembly consists of a spring, a yoke, a weight, a permanent magnet, and a top plate. The stator assembly is placed under the vibrator assembly to have interaction between the magnetic field and the electrical field and generate electromagnetic force on the vibrator assembly. The electrical input signal is applied to the voice coil, and when current flows through the voice coil, a force is generated. The input voltage is an alternating current (AC) signal. The force reverses direction each time the current reverses, so the force on the vibrator assembly causes it to move up and down with the signal.

For maximum force, the magnetic field must be perpendicular to the direction of the current flow. Figure 2 shows an exploded view and a cross-sectional view of the linear vibration motor. Compared to a coin-type vibration motor, a linear vibration motor has some advantages, like faster response time and precise vibration.

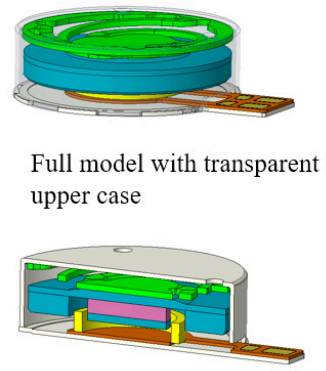

Half model

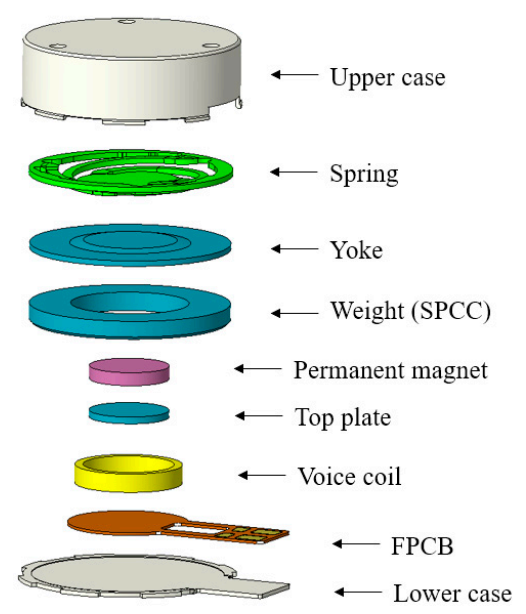

Figure 2. The exploded view and a cross-sectional view of a linear vibration motor.

\subsection{Material Properties}

The linear vibration motor is an electric device with coupling between the electromagnetic field and the mechanical field. The most essential performance of the vibration motor is the acceleration on a dummy jig, which has a size of $105 \times 45 \times 15 \mathrm{~mm}$ and weight of $100 \mathrm{~g}$ as standard test conditions. A base and spring foundation provide almost free constraint. The measurement method for acceleration is shown in Figure 3. The vibration motor should be attached by using double-sided tape on the central upper surface of the dummy jig.

The mechanical properties of the linear vibration motor and dummy jig include the density, Young's modulus, and Poisson's ratio, as shown in Table 1. The material properties of the lower case, spring foundation, and base are the same as those of the upper case, and the FPCB is negligible due to its tiny mass. Cold-rolled carbon steel sheet (SPCC) is a magnetic material, and the magnetic hysteresis (B-H) curve is used to represent its nonlinear magnetic properties, as shown in Figure 4. Permanent magnets are made from magnetized material and produce continual magnetic fields. The material properties of the permanent magnet $(\mathrm{N} 50 \mathrm{H})$ are the remanent flux density $(1.43 \mathrm{~T})$, 
coercivity $(1066 \mathrm{kA} / \mathrm{m})$, and relative permeability (1.07). Moreover, the direct-current resistance (DCR) is $30 \mathrm{ohms}$, and the total coil length is $1.488 \mathrm{~m}$.

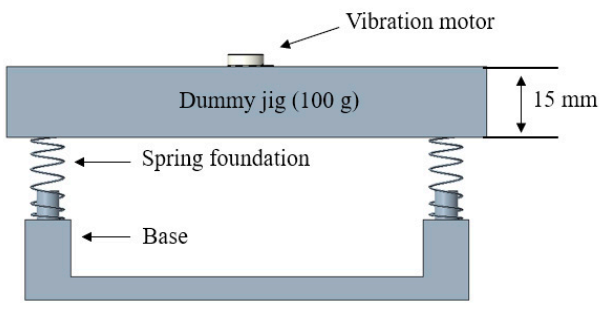

(a)

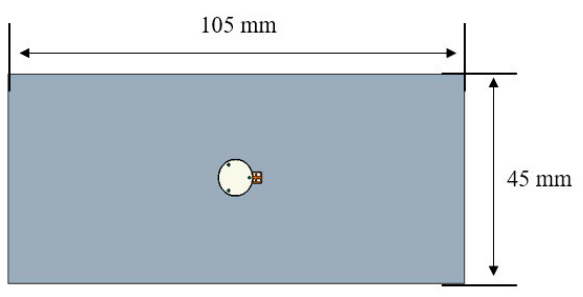

(b)

Figure 3. (a,b) The measurement method for acceleration of the vibration motor.

Table 1. Mechanical properties of the linear vibration motor.

\begin{tabular}{ccccc}
\hline Parts & Material & Density $\left.\mathbf{( k g} / \mathbf{m}^{\mathbf{3}}\right)$ & Young's Modulus (GPa) & Poisson's Ratio \\
\hline Upper case & SUS 304 & 7850 & 193 & 0.25 \\
Spring & SUS 301 EH & 7800 & 110 & 0.28 \\
Yoke/Top plate & SPCC & 7830 & 207 & 0.29 \\
Permanent magnet & Neodymium & 7010 & 160 & 0.30 \\
Voice coil & Copper & 5321 & 126 & 0.34 \\
Dummy jig & Polyoxymethylene & 1417 & 3.15 & 0.30 \\
\hline
\end{tabular}

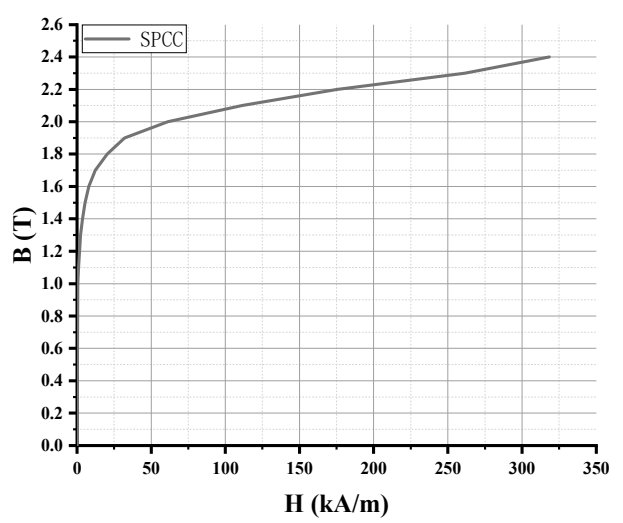

Figure 4. The B-H curve of SPCC.

\section{Analysis Methods}

\subsection{Magnetostatic Analysis}

This study employed a magnetostatic finite element method model of the linear vibration motor to obtain the magnetic field and electromagnetic force. Based on Maxwell's equations [6,7], magnetostatic equations describe magnetic fields that do not vary with time, which are caused by a permanent magnet or by the steady flow of electricity (Direct current). The magnetostatic equations in differential forms are Gauss's magnetic law and Maxwell's-Ampere's law:

$$
\begin{gathered}
\nabla \cdot B=0, \\
\nabla \times H=J,
\end{gathered}
$$

where $\nabla$ with the dot denotes divergence, and $B$ is the magnetic flux density. $\nabla$ with the cross denotes curl, $J$ is the current density, and $H$ is the magnetic field intensity. The magnetic field can be derived from the vector potential as follows:

$$
\nabla \times A=B
$$


where the field $A$ is called the magnetic vector potential. The flux density on voice coil is used to calculate the force factor, which is the transmission factor between the electromagnetic domain and mechanical domain. The Lorentz force resulting from the interaction between the electric current and magnetic field can be expressed as:

$$
F_{\text {Lorentz }}=\oint i d l \times B,
$$

where $i$ and $l$ denote the coil current and total coil length, respectively.

\subsection{Mechanical Analysis}

The static analysis of the mechanical parts is intended to calculate the effects of the constant loads on the structure while ignoring the effects of the inertia and shock that are commonly found when the applied load changes abruptly. The dynamic analysis of the mechanical parts is used to determine the vibrational characteristics. There are two analyses in this sub-section. One is linear stress analysis to check the von Mises stress distribution on the spring. The other is modal analysis to determine the mode frequencies and mode shape from the structures of the spring. The boundary conditions of the mechanical analysis are shown in Figure 5. To observe the boundary conditions easily, the upper case and lower case have been made transparent, and the red areas are the fixed parts for mechanical analyses.

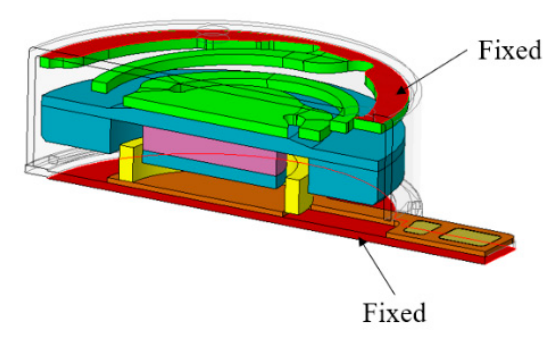

Figure 5. The boundary conditions of the linear vibration motor.

In the static mechanical analysis [8], the governing equation is as follows:

$$
\left[K_{m}\right]\{x\}=\left\{F_{\text {Lorentz }}\right\},
$$

where $\left[K_{m}\right],\{x\}$, and $\left\{F_{\text {Lorentz }}\right\}$ are the stiffness matrix of the vibration motor, displacement vector, and Lorentz force vector, respectively. The Lorentz force is applied on the top plate to obtain the static analysis results. For an isotropic material, the stresses and strains can be represented by column matrices as:

$$
\begin{gathered}
\{\sigma\}=[D]\{\varepsilon\}, \\
{[D]=\frac{E}{(1+v)(1-2 v)}\left[\begin{array}{cccccc}
1-v & v & v & 0 & 0 & 0 \\
v & 1-v & v & 0 & 0 & 0 \\
v & v & 1-v & 0 & 0 & 0 \\
0 & 0 & 0 & \frac{1-2 v}{2} & 0 & 0 \\
0 & 0 & 0 & 0 & \frac{1-2 v}{2} & 0 \\
0 & 0 & 0 & 0 & 0 & \frac{1-2 v}{2}
\end{array}\right],}
\end{gathered}
$$

where $[D], E$, and $v$ denote a constitutive matrix, Young's modulus, and Poisson's ratio, respectively.

Mathematically, the von Mises stress is a scalar value of stress that can be computed from the Cauchy stress tensor components in a general three-dimensional (3D) domain. A material starts yielding when the von Mises stress reaches a value known as the yield strength, $\sigma_{y}$. The von Mises stress is used to predict the yielding of a material under multiaxial loading conditions using results from a simple uniaxial tensile test. 
The Cauchy stress tensor, $\sigma_{i j}$, consists of nine components that completely define the state of stress at a point inside a material in the deformed state:

$$
\begin{gathered}
{\left[\sigma_{i j}\right]=\left[\begin{array}{lll}
\sigma_{11} & \sigma_{12} & \sigma_{13} \\
\sigma_{21} & \sigma_{22} & \sigma_{23} \\
\sigma_{31} & \sigma_{32} & \sigma_{33}
\end{array}\right],} \\
\sigma_{v}^{2}=\frac{1}{2}\left[\left(\sigma_{11}-\sigma_{22}\right)^{2}+\left(\sigma_{22}-\sigma_{33}\right)^{2}+\left(\sigma_{33}-\sigma_{11}\right)^{2}+6\left(\sigma_{23}^{2}+\sigma_{31}^{2}+\sigma_{12}^{2}\right)^{2}\right],
\end{gathered}
$$

where $\sigma_{v}$ is the von Mises stress, and subscripts 1,2 , and 3 denote the $x$-direction, y-direction, and z-direction, respectively. In Figure $6, \sigma_{11}, \sigma_{22}$, and $\sigma_{33}$ represent the normal stresses, while $\sigma_{12}, \sigma_{23}$, and $\sigma_{31}$ are the shear stresses.

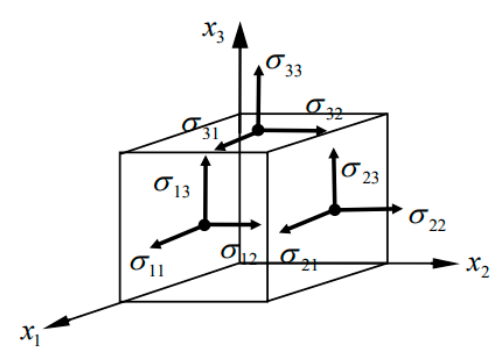

Figure 6. The nine stress components with respect to a Cartesian coordinate system.

The factor of safety (FoS) expresses how much stronger a system is than it needs to be for an intended load [9]. It is defined as the ratio of the yield stress to the working stress for ductile materials. The working stress is selected as the maximum von Mises stress in this study.

$$
\text { Factor of Safety }=\frac{\text { Yield stress } \sigma_{y}}{\text { Maximum von Mises stress }} .
$$

\subsection{Electromagnetic-Mechanical Coupling Method}

The voltage equation of the linear vibration motor is described as follows:

$$
V=i R+B l \dot{x},
$$

where $V, R$, and $\dot{x}$ denote the driving voltage, coil resistance, and velocity of the mechanical vibrator assembly, respectively. The back electromotive force is generated by the coil motion against the driving voltage due to Faraday's law [10]:

$$
V_{\text {back }}=B l \dot{x},
$$

where $B l$ is defined as a force factor with note units.

The force factor can be obtained by magnetostatic analysis. The mechanical vibration equation of the spring-damping-mass system can be developed using a 3D finite element method. The mechanical response can be obtained by solving the electromagnetic-mechanical coupling equation:

$$
\begin{gathered}
{\left[M_{m}\right]\left\{\ddot{x}_{m}\right\}+\left[C_{m}\right]\left\{\dot{x}_{m}\right\}+\left[K_{m}\right]\left\{x_{m}\right\}=\left\{F_{\text {Lorentz }}\right\},} \\
{\left[M_{d}\right]\left\{\ddot{x}_{d}\right\}+\left[K_{d}\right]\left\{x_{d}\right\}=\left\{F_{\text {Transimit }}\right\},}
\end{gathered}
$$

where $\left[M_{m}\right]$ and $\left[C_{m}\right]$ denote the mass matrix of the vibration moor and the damping coefficient matrix of the vibration motor. $\left[M_{d}\right]$ and $\left[K_{d}\right]$ denote the mass matrix and stiffness coefficient matrix of the dummy jig, respectively. $\left\{F_{\text {Transimit }}\right\}$ is the driving force applied on the dummy jig, which is transmitted from the vibration motor. The damping coefficient matrix of the dummy jig has been 
ignored. A diagram of the mechanical vibration system and electromagnetic-mechanical coupling method are shown in Figures 7 and 8, respectively.

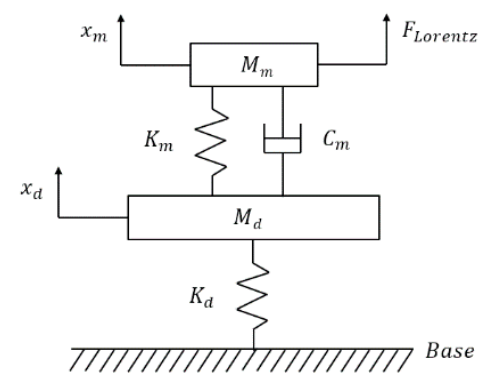

Figure 7. Diagram of the mechanical vibration system.

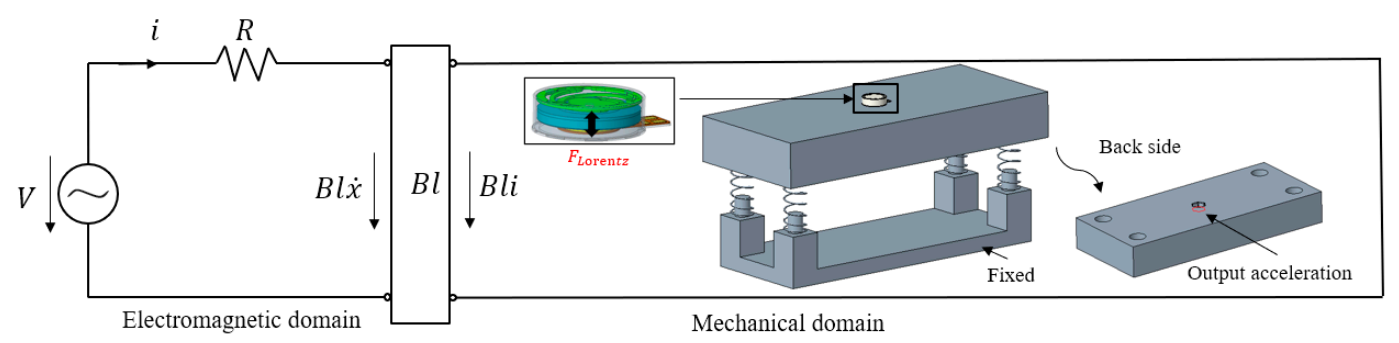

Figure 8. Diagram of the electromagnetic-mechanical coupling method.

\subsection{Samples}

The vibration motor is inserted in an E-cigarette's lower part that users grab. The design principle is that a user can feel haptic feedback directly when the vibration motor is mounted in this position. A sample and 3D model of an E-cigarette are shown in Figure 9, and the total mass of the E-cigarette is $81.83 \mathrm{~g}$.

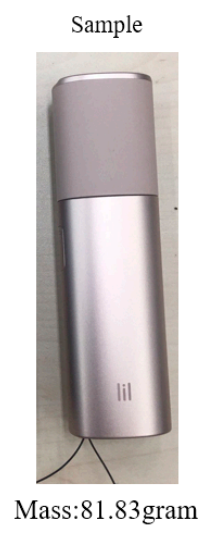

(a)

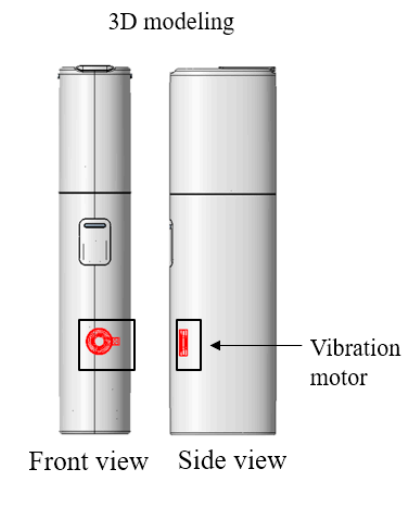

(b)

Figure 9. (a) Sample and (b) three-dimensional (3D) model of an E-cigarette.

The coin-type vibration motor is shown in Figure 10 with the front side and back side. Each component of the linear vibration motor is shown in Figure 11. The 3D model of the prototype spring is the same as the manufactured spring sample, as shown in Figure 12. These vibration motors were used to do experiments to obtain the acceleration on a dummy jig. 


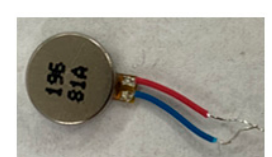

Front side

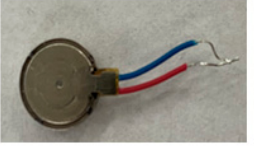

Back side

Figure 10. The coin-type vibration motor sample.

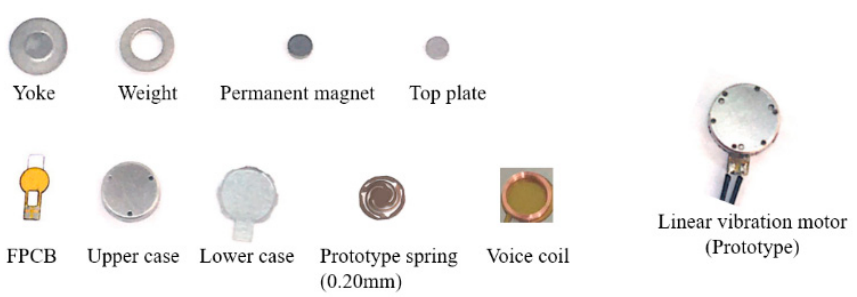

Figure 11. Each component of the linear vibration motor sample prototype.
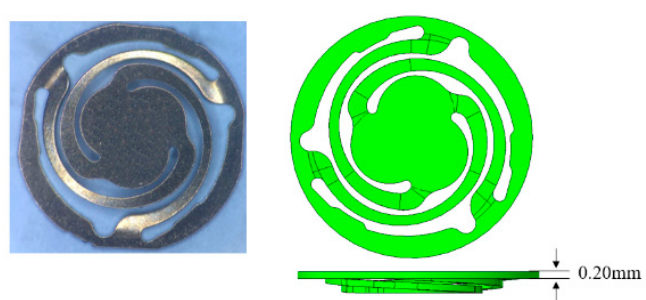

Figure 12. Sample and 3D model of the prototype spring (thickness $=0.20 \mathrm{~mm}$ ).

\subsection{Experimental Setup}

The experimental setup for measuring the acceleration on the testing jig includes a computer, a monitor, a mouse, and a keyboard, a vibration tester (Type BK 2120C2), a testing jig, and a vibration motor, as shown in Figure 13. The testing jig consists of a base, 4 spring foundations, a $100 \mathrm{~g}$ dummy jig, and an accelerometer. The detailed components of the testing are shown in Figure 14 . When the sinusoidal voltage is applied to the vibration motor, the motor vibration and the acceleration on the dummy jig can be detected by an accelerometer. The acceleration is converted from a time-domain signal to a frequency-domain signal through a preamplifier and fast Fourier transform (FFT) analysis inside the vibration tester, and the results are displayed on the screen.

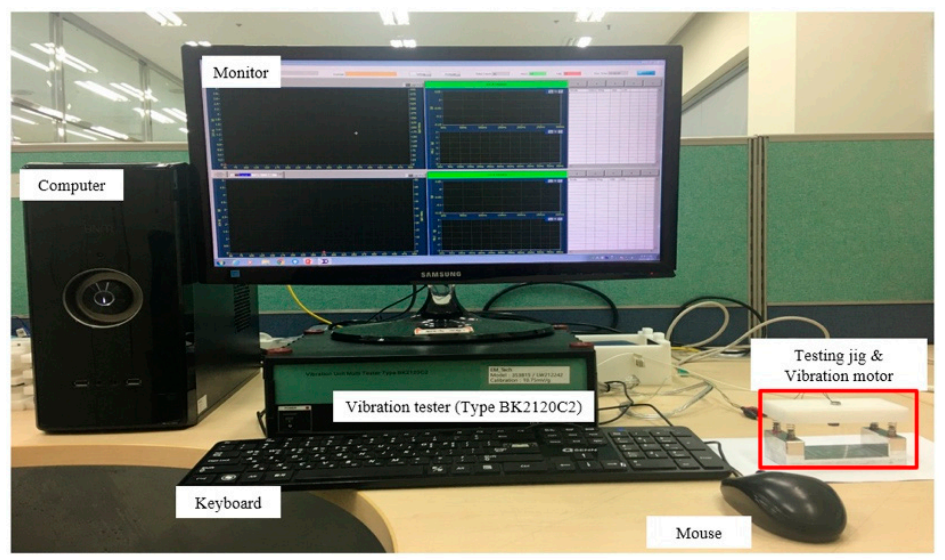

Figure 13. The acceleration measurement setup under standard test conditions. 

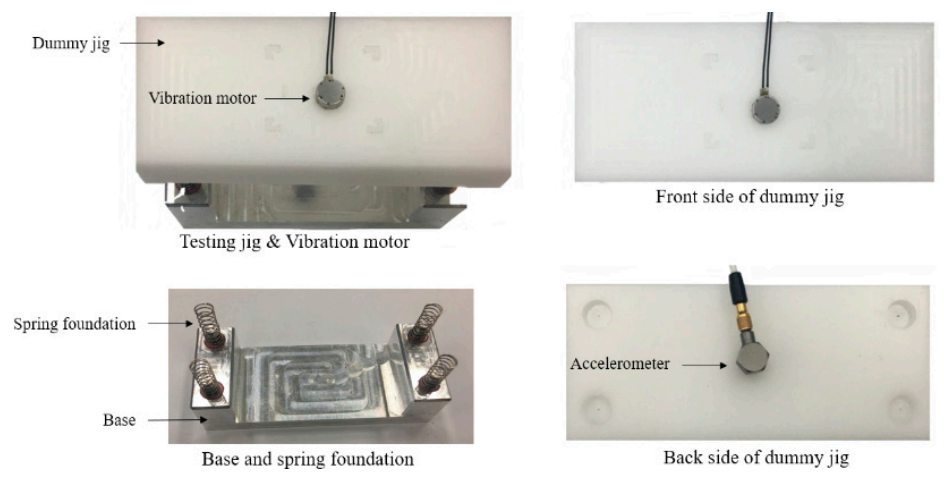

Figure 14. The detailed components of the acceleration testing jig.

A vibration motor is designed to provide haptic feedback to a human by vibrating human skin. According to mechanoreceptors [11], the Pacinian corpuscles in the skin and fascia can detect rapid vibrations of around $200-300 \mathrm{~Hz}$. In addition, the most sensitive frequency of the human finger is around $250 \mathrm{~Hz}[12,13]$.

The coin-type vibration motor has been used for E-cigarettes for a long time, so its acceleration was measured as reference data. Two input voltages were used for the prototype linear vibration experiment. One is $0.5 \mathrm{~V}$ to check the resonance frequency of the vibration motor. The other is $4.35 \mathrm{~V}$ to measure the acceleration performance from 100 to $300 \mathrm{~Hz}$. Furthermore, the final excited frequency range is from 240 to $260 \mathrm{~Hz}$ at $4.35 \mathrm{~V}$.

A comparison between the experiment results of the acceleration on the dummy jig of the prototype with different voltages is shown in Figure 15. The analysis results are in good agreement with the experiment results. The acceleration of the prototype $(0.021 \mathrm{~g})$ is $86.0 \%$ lower than that of the coin-type vibration motor $(0.15 \mathrm{~g})$ at $250 \mathrm{~Hz}$, which is a significant problem that needs to be solved. Based on the same analysis methods, there are several designs listed in the next section, and the analysis results of the novel design were verified by experiment results.

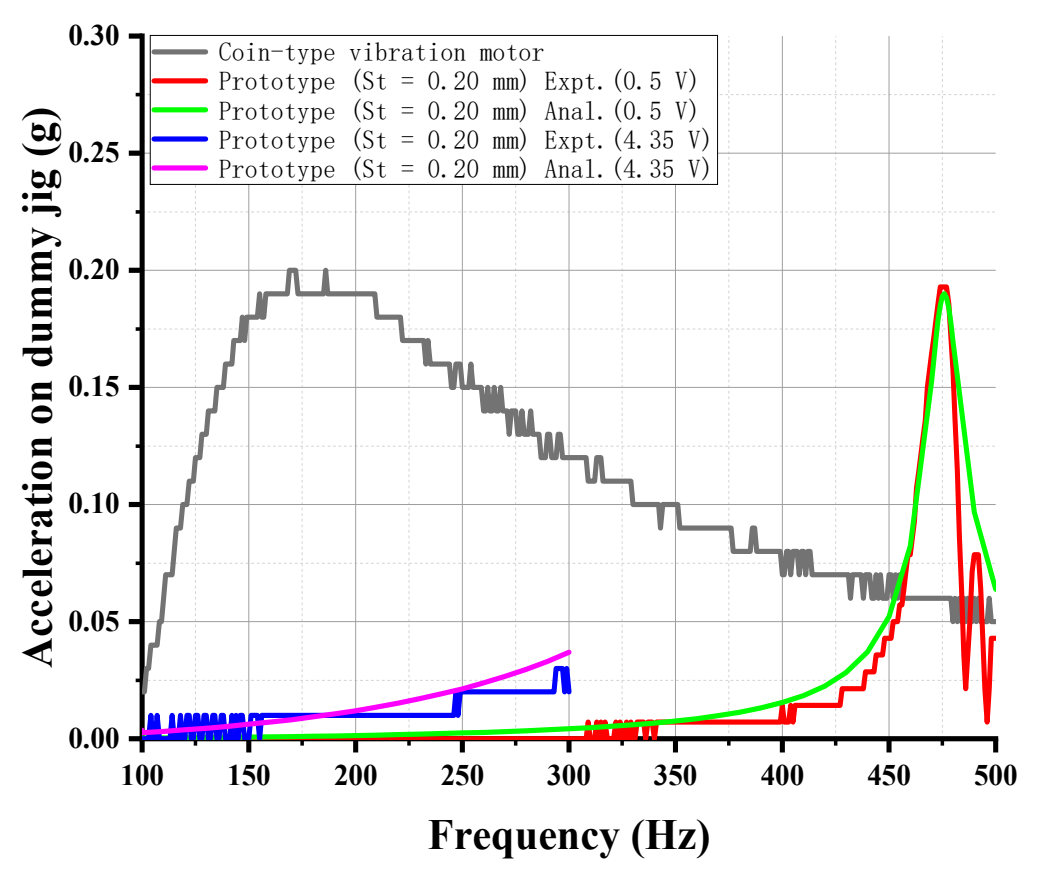

Figure 15. Acceleration comparison between coin-type vibration motor and prototype linear vibration motor. 


\section{Design and Optimization}

The target for the linear vibration motor is to have a similar acceleration to that of coin-type vibration motors at $250 \mathrm{~Hz}$. However, the prototype cannot reach the design target. In this section, the spring shape design, spring thickness design, and magnetic circuit design and optimization are discussed in detail. The resonance frequency and excitation force are the two essential factors that affect the acceleration. In the linear mechanical vibration system, it is effective to reduce the resonance frequency of the linear vibration motor by increasing the movable mass or decreasing the spring constant.

However, the movable mass consists of the yoke, weight, magnet, and top plate, which are electromagnetic. Thus, it is not suitable to reduce the resonance frequency for this linear vibration motor by increasing the movable mass. The focus of this study is spring design in order to reduce the resonance frequency and magnetic circuit optimization to improve the acceleration on the dummy jig.

\subsection{Spring Shape Designs}

According to the linear stress analysis, the Lorentz force of the prototype vibration motor is $0.059 \mathrm{~N}$, with a flux density of $0.273 \mathrm{~T}$ and input voltage of $4.35 \mathrm{~V}$, which is applied on the top plate via the direction of the vibration. The von Mises stress distribution on the prototype spring is shown in Figure 16. Six areas have been selected to view the von Mises stress distribution on a single spring rib. The von Mises stress of each area is the average value of the six areas.
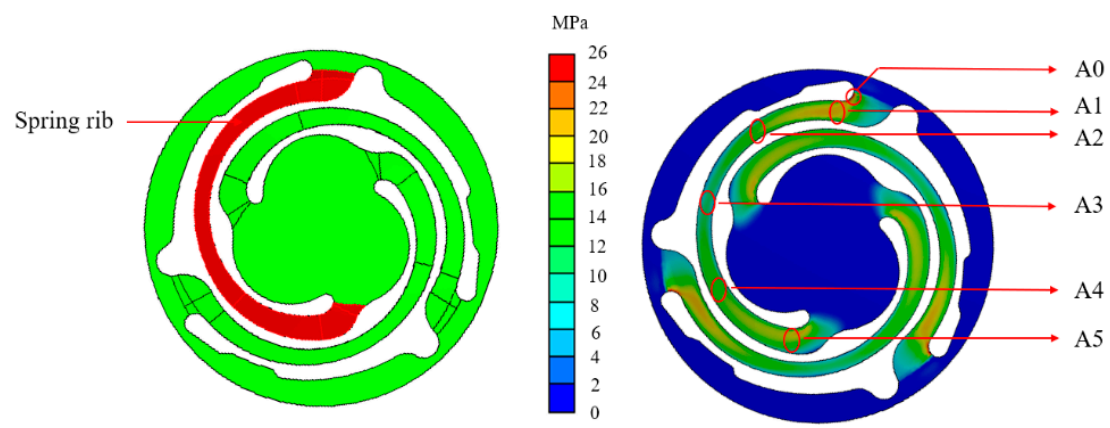

Figure 16. von Mises stress distribution on prototype spring shape.

The von Mises stresses on six areas are shown in Table 2, which shows that the distribution is not a declining distribution but a U-shaped distribution that first drops and then rises. The maximum value is $25.50 \mathrm{MPa}$ at $\mathrm{A} 0$, and minimum value is $10.62 \mathrm{MPa}$ at $\mathrm{A} 3$. The yield stress of SUS $301 \mathrm{EH}$ is $1080 \mathrm{MPa}$, and FoS of the prototype spring is about $42.35(>>1)$, which means the system can work safely under this condition. However, in order to significantly reduce the resonance frequency of the prototype spring, four parts on a spring rib have been selected as design parameters, as shown in Figure 17.

The design parameters Round \#1, Round \#2, Width \#1, and Width \#2 are 0.28, 1.05, 0.30, and $0.40 \mathrm{~mm}$ respectively, which are within the manufacturing limitations. Round \#1 is the first parameter related to A0 and A1. The bigger the round radius, the higher the maximum von Mises stress is, and the lower the resonance frequency is. From Figure 18 and Table 3, it is clear that the von Mises stress at A1 of type \#2 has an $11.89 \%$ increase compared with the prototype spring. At the same time, due to the area reduction on A1 and increased displacement, the von Mises stresses in the other areas of type \#2 have not significantly changed.

Round \#2 is the second parameter related to $\mathrm{A} 0$ and $\mathrm{A} 1$. When the round radius was increased from 0.65 to $1.05 \mathrm{~mm}$, there was no significant increase in the von Mises stress at A0 and A1 because the location of round \#2 is a little bit far away from A0 and A1. However, the resonance frequency still slightly decreased. This means that the type \#4 spring with a smooth shape of round \#2 can be easier to vibrate than the prototype spring. The von Mises stress distribution for different round \#2 parameters is shown in Figure 19. The analysis results are compared in Table 4. 
Table 2. von Mises stress at selected areas on prototype spring shape.

\begin{tabular}{cc}
\hline Areas & von Mises Stress $\mathbf{( M P a )}$ \\
\hline A0 & 25.50 \\
A1 & 22.03 \\
A2 & 17.31 \\
A3 & 10.62 \\
A4 & 16.14 \\
A5 & 20.28 \\
\hline
\end{tabular}

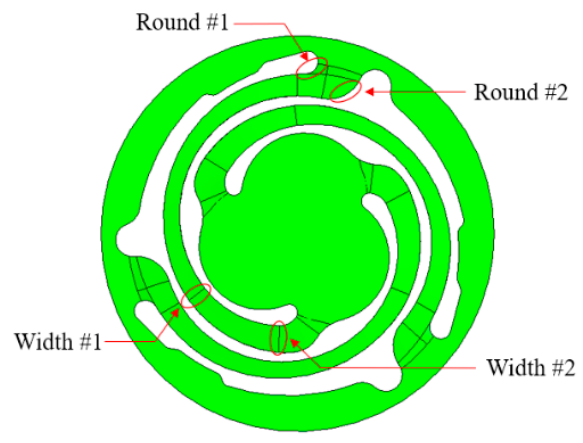

Figure 17. Four design parameters on prototype spring.
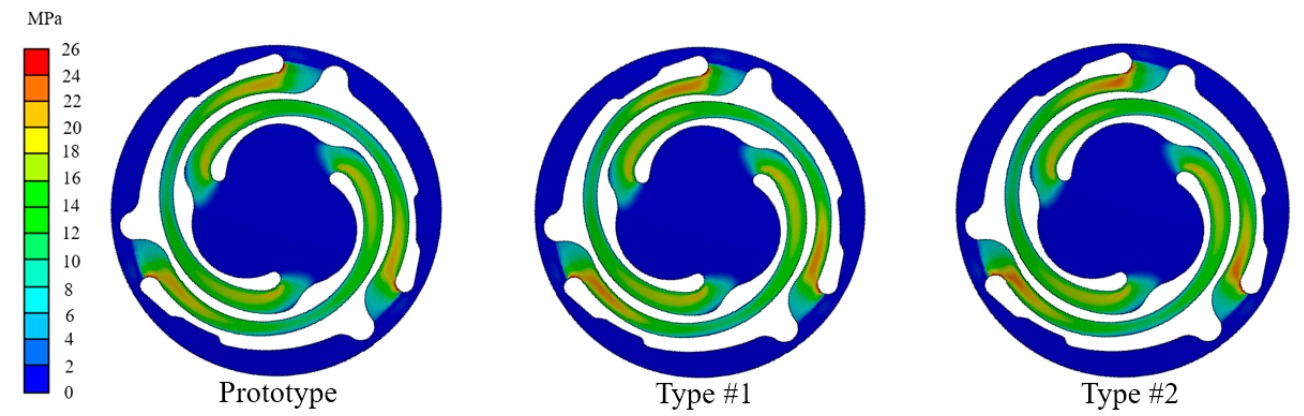

Figure 18. von Mises stress distribution on spring with different round \#1 parameters.

Table 3. Analysis result comparison between different round \#1 parameters.

\begin{tabular}{cccc}
\hline Items & Prototype & Type \#1 & Type \#2 \\
\hline Round \#1 parameters $(\mathrm{mm})$ & 0.24 & 0.26 & 0.28 \\
Maximum von Mises stress $(\mathrm{MPa})$ & 25.50 & $25.76(+1.02 \%)$ & $25.91(+1.61 \%)$ \\
von Mises stress at A1 $(\mathrm{MPa})$ & 22.03 & $23.48(+6.58 \%)$ & $24.65(+11.89 \%)$ \\
Resonance frequency $(\mathrm{Hz})$ & 476.18 & $470.92(-1.10 \%)$ & $463.25(-2.72 \%)$ \\
Displacement at top plate $(\mu \mathrm{m})$ & 25.87 & $26.45(+2.24 \%)$ & $27.34(+5.68 \%)$ \\
\hline
\end{tabular}
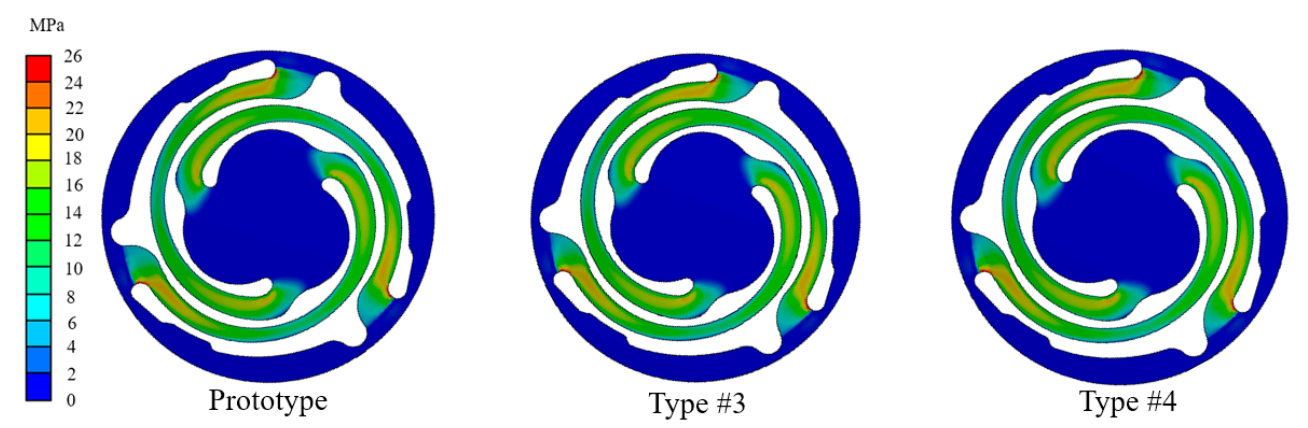

Figure 19. von Mises stress distribution on spring with different round \#2 parameters. 
Table 4. Analysis result comparison between different round \#2 parameters.

\begin{tabular}{cccc}
\hline Items & Prototype & Type \#3 & Type \#4 \\
\hline Round \#2 parameters $(\mathrm{mm})$ & 0.65 & 0.85 & 1.05 \\
Maximum von Mises stress $(\mathrm{MPa})$ & 25.50 & $25.55(+0.20 \%)$ & $25.61(+0.43 \%)$ \\
von Mises stress on A1 $(\mathrm{MPa})$ & 22.03 & $22.17(+0.64 \%)$ & $22.21(+0.82 \%)$ \\
Resonance frequency $(\mathrm{Hz})$ & 476.18 & $474.85(-0.28 \%)$ & $473.52(-0.56 \%)$ \\
Displacement at top plate $(\mu \mathrm{m})$ & 25.87 & $26.02(+1.28 \%)$ & $26.16(+1.12 \%)$ \\
\hline
\end{tabular}

Width \#1 is the third parameter related to A4. When width \#1 decreases from 0.40 to $0.30 \mathrm{~mm}$, there is a significant increase in the von Mises stress at A4 due to the area reduction. Meanwhile, the maximum von Mises stress has a $1.29 \%$ increase at A0 according to the bigger displacement at the top plate with a reduction in resonance frequency $(-2.49 \%)$. In Figure 20, the von Mises stresses in the other areas do not have much difference when decreasing width \#1. The analysis results are compared in Table 5.
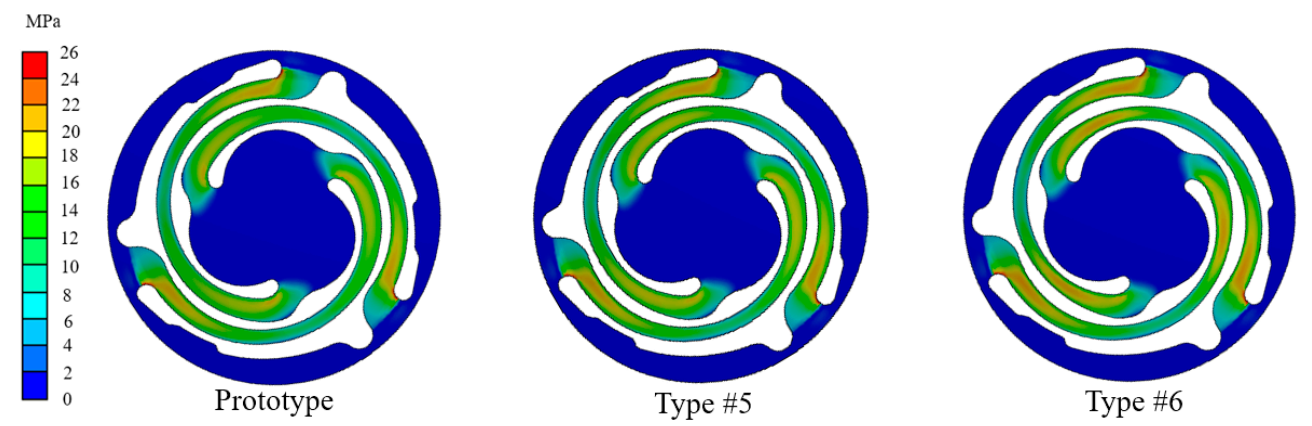

Figure 20. von Mises stress distribution on spring with different width \#1 parameters.

Table 5. Analysis result comparison between different width \#1 parameters.

\begin{tabular}{cccc}
\hline Items & Prototype & Type \#5 & Type \#6 \\
\hline Width \#1 parameters $(\mathrm{mm})$ & 0.40 & 0.35 & 0.30 \\
Maximum von Mises stress $(\mathrm{MPa})$ & 25.50 & $25.68(+0.71 \%)$ & $25.83(+1.29 \%)$ \\
von Mises stress on A4 $(\mathrm{MPa})$ & 16.14 & $18.53(+14.81 \%)$ & $20.30(+25.77 \%)$ \\
Resonance frequency $(\mathrm{Hz})$ & 476.18 & $468.70(-1.57 \%)$ & $464.32(-2.49 \%)$ \\
Displacement at top plate $(\mu \mathrm{m})$ & 25.87 & $26.71(+3.25 \%)$ & $27.21(+5.18 \%)$ \\
\hline
\end{tabular}

Width \#2 is the fourth parameter related to A5. The von Mises stress at A5 has a significant increase of about $21.40 \%$ when width \#2 decreases from 0.50 to $0.40 \mathrm{~mm}$. The maximum von Mises stress of type \#8 is $25.88 \mathrm{MPa}$, which has a $1.49 \%$ increase at A0 due to the bigger displacement at the top plate. The resonance frequency has a $3.32 \%$ reduction compared to the prototype spring. The analysis results are shown in Figure 21 and Table 6.
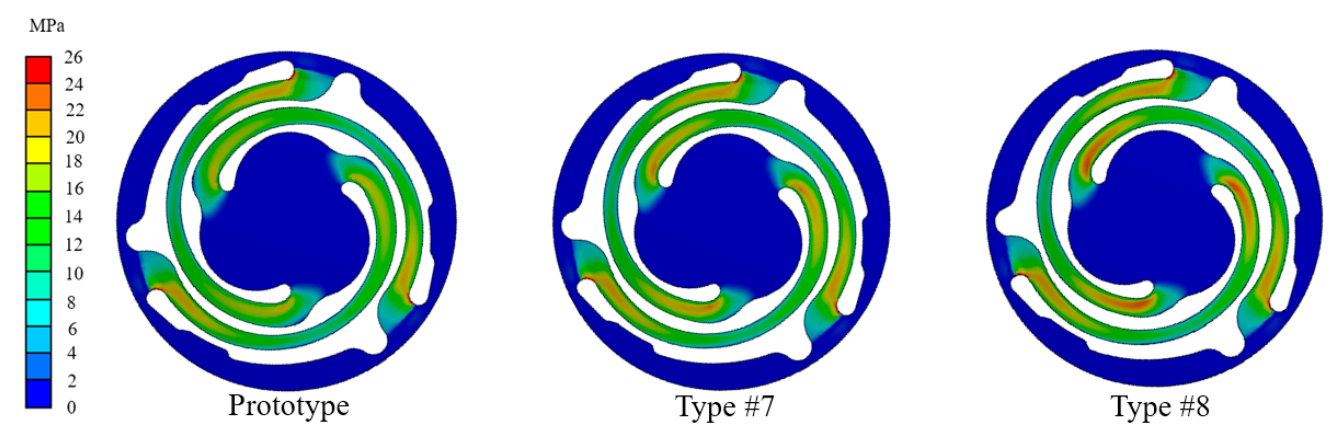

Figure 21. von Mises stress distribution on spring with different width \#2 parameters. 
Table 6. Analysis result comparison between different width \#2 parameters.

\begin{tabular}{cccc}
\hline Items & Prototype & Type \#7 & Type \#8 \\
\hline Width \#2 parameters $(\mathrm{mm})$ & 0.50 & 0.45 & 0.40 \\
Maximum von Mises stress $(\mathrm{MPa})$ & 25.50 & $25.70(+0.78 \%)$ & $25.88(+1.49 \%)$ \\
von Mises stress on A5 $(\mathrm{MPa})$ & 20.28 & $22.37(+10.31 \%)$ & $24.62(+21.40 \%)$ \\
Resonance frequency $(\mathrm{Hz})$ & 476.18 & $467.02(-1.92 \%)$ & $460.35(-3.32 \%)$ \\
Displacement at top plate $(\mu \mathrm{m})$ & 25.87 & $26.90(+3.98 \%)$ & $27.68(+7.00 \%)$ \\
\hline
\end{tabular}

From the analysis results of the four parameters, round \#1, width \#1, and width \#2 have a bigger influence on the resonance frequency by about $2.72 \%, 2.49 \%$, and $3.32 \%$ decrease, respectively. Round \#2 also influences the resonance frequency, making the spring smooth to vibrate. The maximum von Mises stress occurs with $1.61 \%$ and $1.49 \%$ increases in round \#1 and width \#2, respectively. The FoSs of type \#2 and type \#8 are 41.68 and 41.73 , respectively, which are a little bit smaller than that of the prototype. However, the FoSs of these types are still significantly higher than 1.

To minimize the resonance frequency and keep the maximum von Mises stress as low as possible, a novel spring has been proposed with round \#1, round \#2, width \#1, and width \#2 values of 0.26 , $1.05,0.30$, and $0.40 \mathrm{~mm}$, respectively. The contact area is reduced from 9.72 to $8.05 \mathrm{~mm}^{2}$ to increase the gap between the spring rib and contact to avoid mechanical interference. The spring thickness (St) is $0.20 \mathrm{~mm}$. The analysis results are shown in Figure 22 and Table 7. Compared to the prototype spring, the resonance frequency of novel spring \#1 has a $4.37 \%$ decrease, and the maximum von Mises stress has a $1.88 \%$ increase. The FoS of novel spring \#1 is 41.57 , which is not much different from the prototype spring.
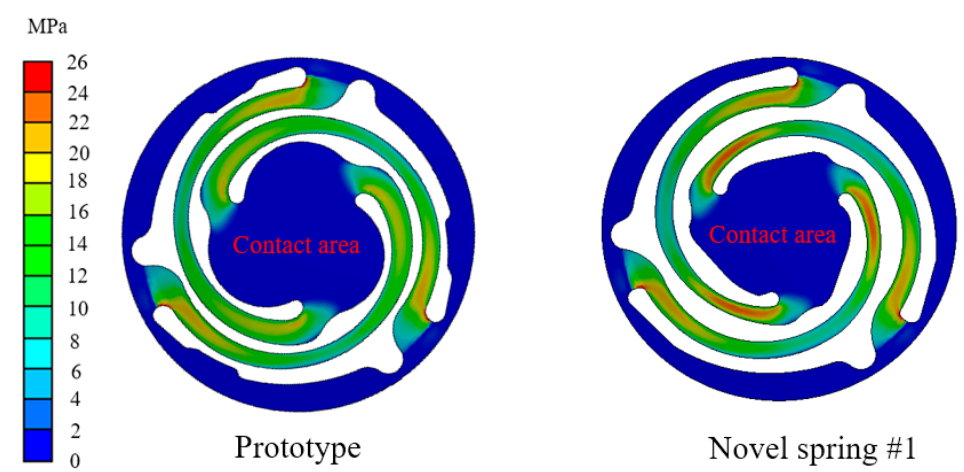

Figure 22. von Mises stress distribution on prototype spring and novel spring.

Table 7. Analysis result comparison between prototype spring and novel spring.

\begin{tabular}{ccc}
\hline Items & Prototype $(\mathbf{S t}=\mathbf{0 . 2 0} \mathbf{~ m m})$ & Novel Spring \#1 $(\mathbf{S t}=\mathbf{0 . 2 0} \mathbf{~ m m})$ \\
\hline Maximum von Mises stress $(\mathrm{MPa})$ & 25.50 & $25.98(+1.88 \%)$ \\
Resonance frequency $(\mathrm{Hz})$ & 476.18 & $455.36(-4.37 \%)$ \\
Displacement at top plate $(\mu \mathrm{m})$ & 25.87 & $28.29(+9.35 \%)$ \\
\hline
\end{tabular}

\subsection{Spring Thickness Design}

Based on analysis results of novel spring \#1, the resonance frequency is still higher than $250 \mathrm{~Hz}$. In this sub-section, the spring thickness is another design parameter, which can also affect the spring stiffness constant. The St values include $0.20,0.15$, and $0.13 \mathrm{~mm}$, with the same spring rib shape. The analysis results are compared in Figure 23 and Table 8.

A thinner spring leads to a big displacement that causes higher von Mises stress. The displacement at the top plate of novel spring \#2 and novel spring \#3 has $84.76 \%$ and $163.80 \%$ increases compared to novel spring \#1, respectively. The maximum von Mises stress of novel spring \#3 increases about $31.33 \%$ at $\mathrm{A} 0$, and the FoS (31.65) is still higher than 1 , which means failure of the structure of the spring will 
not occur under the current condition. After the spring shape design and spring thickness design, the resonance frequency of novel spring \#3 is close to $250 \mathrm{~Hz}$. Novel spring \#2 and novel spring \#3 were selected for manufacturing.
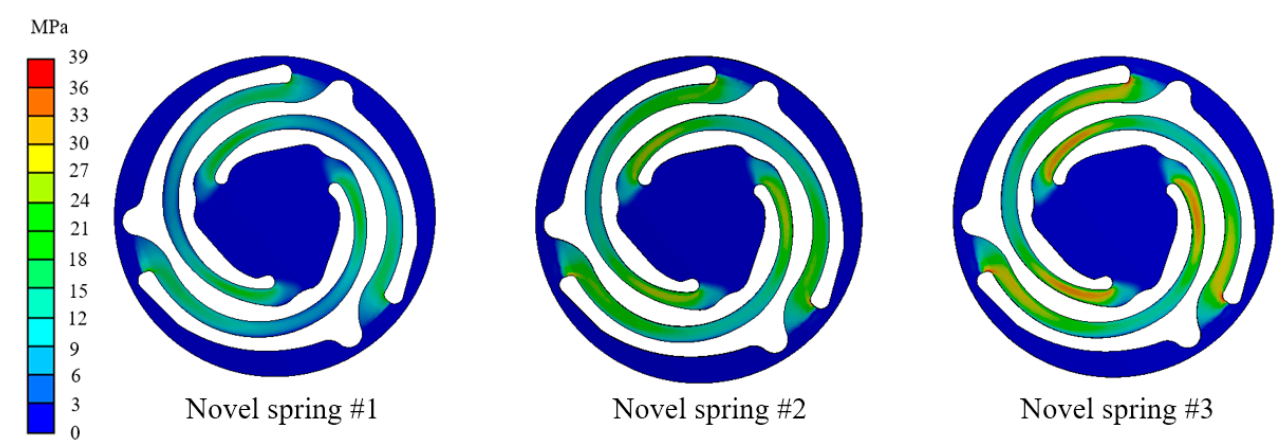

Figure 23. von Mises stress distribution on novel spring with different spring thicknesses.

Table 8. Analysis result comparison between different spring thicknesses.

\begin{tabular}{cccc}
\hline Items & $\begin{array}{c}\text { Novel Spring \#1 } \\
(\mathbf{S t}=\mathbf{0 . 2 0} \mathbf{~ m m})\end{array}$ & $\begin{array}{c}\text { Novel Spring \#2 } \\
(\mathbf{S t}=\mathbf{0 . 1 5} \mathbf{~ m m})\end{array}$ & $\begin{array}{c}\text { Novel Spring \#3 } \\
(\mathbf{S t}=\mathbf{0 . 1 3} \mathbf{~ m m})\end{array}$ \\
\hline Maximum von Mises stress $(\mathrm{MPa})$ & 25.98 & $30.73(+18.28 \%)$ & $34.12(+31.33 \%)$ \\
Resonance frequency $(\mathrm{Hz})$ & 455.36 & $335.01(-26.43 \%)$ & $280.38(-38.43 \%)$ \\
Displacement at top plate $(\mu \mathrm{m})$ & 28.29 & $52.27(+84.76 \%)$ & $74.63(+163.80 \%)$ \\
\hline
\end{tabular}

\subsection{Yoke Shape Design}

Both the yoke and weight are magnetic materials (SPCC), which have high nonlinear magnetic permeabilities to allow high magnetic flux to pass through. The magnetic flux density distributions of three yoke shapes are shown in Figure 24. All of them have the same magnetic flux density $(0.273 \mathrm{~T})$. The prototype's yoke shape is a flat circular plate with a small chamfer to avoid mechanical interference between the spring and yoke. Novel yoke shape \#1 is a Z-shape yoke with the same chamfer but an easy way to hold the weight, while novel yoke shape \#2 is an L-shape yoke.
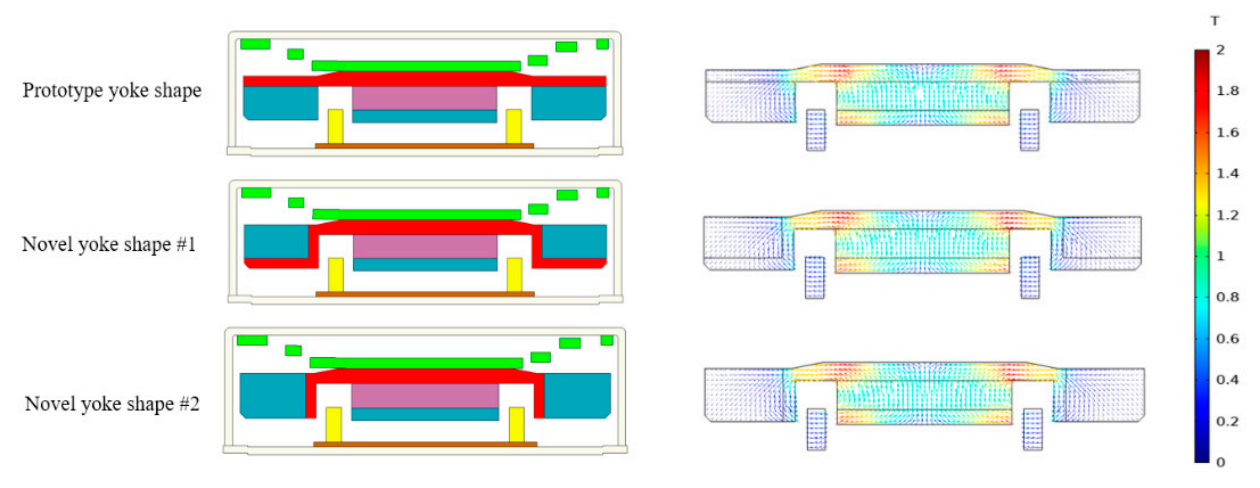

Figure 24. Novel yoke shapes and flux density distribution.

The manufacturing cost depends on the complexity of the yoke shape. Novel shape \#2 needs a bending operation based on the prototype yoke shape, and novel yoke shape \#1 needs one more bending operation. Thus, the order of the manufacturing cost of the three yoke shapes from high to low is novel yoke shape \#2, novel yoke shape \#1, and the prototype shape. The target of this design is to reduce the manufacturing cost while keeping the same performance. Thus, the prototype yoke shape was used for magnetic circuit optimization. 


\subsection{Magnetic Circuit Optimization}

The Lorentz force applied on the vibration assembly is linearly related to the current in the voice coil. It can be divided into two components. One is current on voice current, and the other is a force factor that consists of the magnetic flux density and total coil length. The input voltage and specifications of the voice coil are fixed. Magnetic circuit optimization (MCO) is used to maximize the Lorentz force by changing the magnetic structure dimensions.

The total thickness of the magnetic structure (yoke, magnet, and top plate) is fixed at $1.03 \mathrm{~mm}$. The thickness from the yoke to the weight is fixed at $0.88 \mathrm{~mm}$. Each magnetic circuit component and constraint has been marked with a number in Figure 25. MCO \#1 and MCO \#2 have different magnet thickness (MG) with the same yoke thickness (YK). When MG decreases, the top plate thickness $(\mathrm{T} / \mathrm{P})$ increases.

MCO \#3 and MCO \#4 are models with different T/P and the same MG. When T/P decreases, YK increases, resulting in decreasing weight thickness. MCO \#5 and MCO \#6 have different YK with the same T/P. When YK decreases, MG increases, which also causes the weight thickness to increase. The thicknesses of each magnetic circuit component are shown in Table 9.

The analysis result of the average flux density, force factor, and Lorentz force are shown in Table 10. The optimized result is MCO \#2, which has a bigger magnet volume. By comparing all analysis results, it can be found that the magnet thickness is the most essential factor. The Lorentz force of MCO \#2 has a $5.36 \%$ increase over that of novel spring \#3. According to the different novel spring thicknesses, the average flux density differs a little when the relative coil position changes. Based on optimized magnetic circuit results, a new MG $(0.53 \mathrm{~mm})$ and T/P $(0.20 \mathrm{~mm})$ were applied to novel linear vibration motors, and samples were manufactured to conduct experiments.

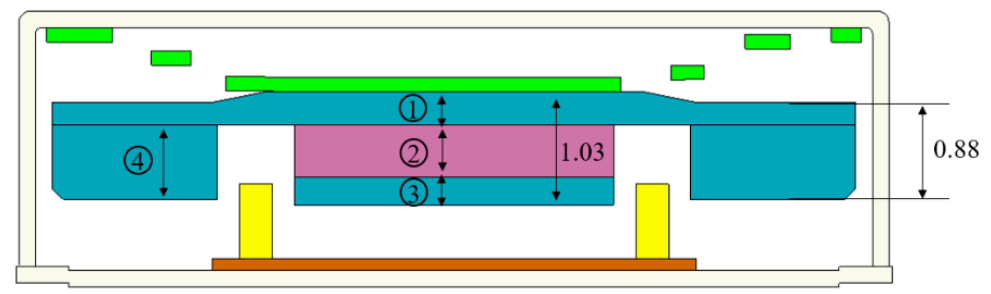

Figure 25. Thicknesses of the magnetic circuit components.

Table 9. Magnetic circuit design parameters.

\begin{tabular}{ccccc}
\hline Types & $\begin{array}{c}\text { Yoke } \\
\text { (1) }\end{array}$ & $\begin{array}{c}\text { Magnet } \\
\text { (2) }\end{array}$ & $\begin{array}{c}\text { Top Plate } \\
\text { (3) }\end{array}$ & $\begin{array}{c}\text { Weight } \\
\text { (4) }\end{array}$ \\
\hline Novel type\#3 & 0.30 & 0.48 & 0.25 & 0.68 \\
MCO \#1 (MG decrease) & 0.30 & 0.43 & 0.30 & 0.68 \\
MCO \#2 (MG increase) & 0.30 & 0.53 & 0.20 & 0.68 \\
MCO \#3 (T/P decrease) & 0.35 & 0.48 & 0.20 & 0.63 \\
MCO \#4 (T/P increase) & 0.25 & 0.48 & 0.30 & 0.73 \\
MCO \#5 (YK decrease) & 0.25 & 0.53 & 0.25 & 0.73 \\
MCO \#6 (YK increase) & 0.35 & 0.43 & 0.25 & 0.63 \\
\hline
\end{tabular}

Table 10. Analysis result comparison of the magnetic circuit optimization.

\begin{tabular}{cccc}
\hline Types & Average Flux Density (T) & Force Factor (N/A) & Lorentz Force (N) \\
\hline Novel type \#3 & 0.261 & 0.388 & 0.056 \\
MCO \#1 (MG decrease) & 0.245 & 0.365 & $0.053(-5.36 \%)$ \\
MCO \#2 (MG increase) & 0.273 & 0.407 & $0.059(+5.36 \%)$ \\
MCO \#3 (T/P decrease) & 0.252 & 0.375 & $0.054(-3.57 \%)$ \\
MCO \#4 (T/P increase) & 0.268 & 0.399 & $0.058(+3.57 \%)$ \\
MCO \#5 (YK decrease) & 0.262 & 0.390 & $0.057(+1.79 \%)$ \\
MCO \#6 (YK increase) & 0.261 & 0.388 & 0.056 \\
\hline
\end{tabular}




\section{Results and Discussion}

\subsection{Novel Vibration Motor Samples and Experiments}

After finishing the design of the spring shape, spring thickness, and magnetic circuit optimization, novel motor samples were made to conduct an experiment. The novel spring sample is shown in Figure 26. There were two thicknesses: 0.15 and $0.13 \mathrm{~mm}$.

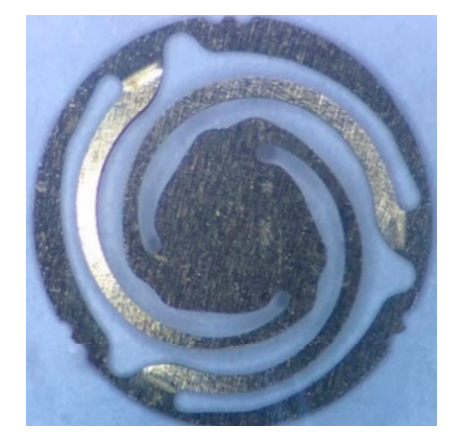

Figure 26. Novel spring sample $(\mathrm{St}=0.15 \mathrm{~mm})$.

\subsection{Result Comparison}

The E-M coupled analysis results are shown in Figure 27, which shows that the experiment results have good agreement with the analysis results when the input voltage is $0.5 \mathrm{~V}$. The acceleration on the dummy jig with the final input voltage $(4.35 \mathrm{~V})$ are shown in Figure $28 \mathrm{a}$. The dotted lines are the values predicted using the E-M coupled method. Figure 28b shows the enlarged results of Figure 28a for more clarity with an input voltage of $4.35 \mathrm{~V}$. The novel type with $\mathrm{St}=0.13 \mathrm{~mm}$ has a higher acceleration value $(0.21 \mathrm{G})$ than the coin-type vibration motor $(0.15 \mathrm{G})$ at $250 \mathrm{~Hz}$, which is a significant improvement of about $40.0 \%$. The specifications of the coin-type vibration motor and novel linear vibration motor are shown in Table 11.

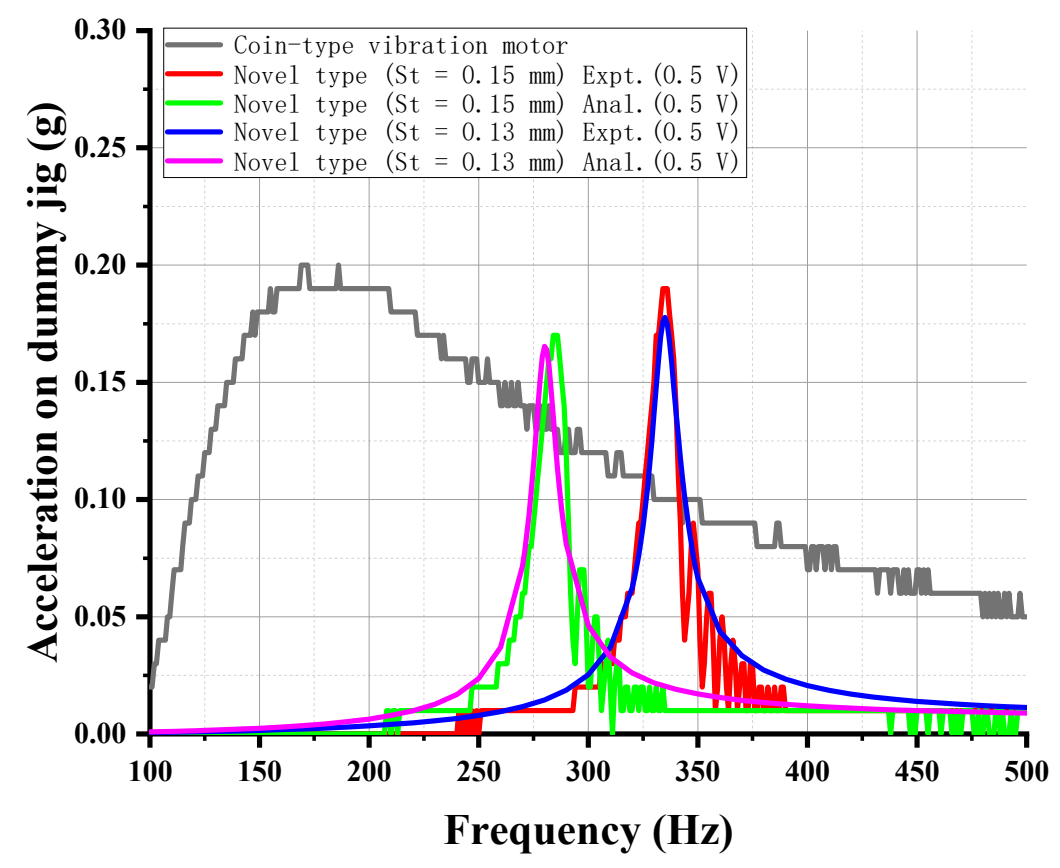

Figure 27. Acceleration comparison between coin-type vibration motor and novel linear vibration motors. 


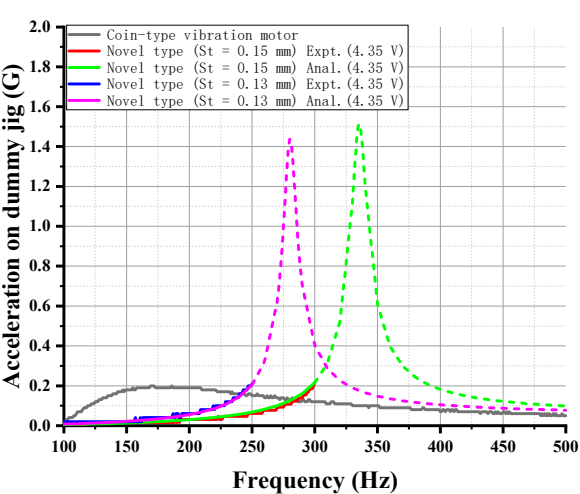

(a)

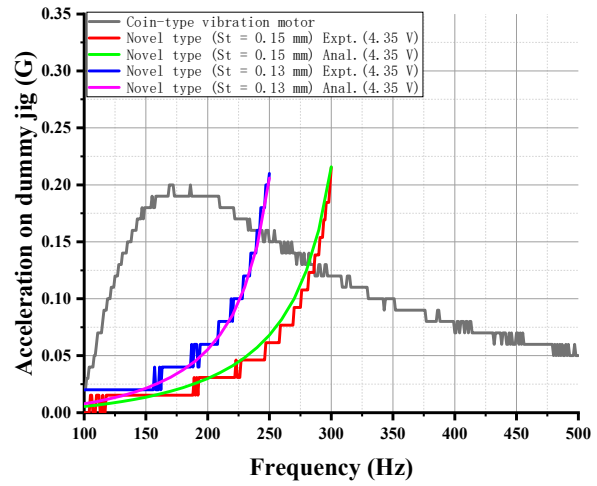

(b)

Figure 28. Acceleration comparison between coin-type vibration motor and novel linear vibration motors (4.35 V): (a) Acceleration from 100 to $500 \mathrm{~Hz},(\mathbf{b})$ acceleration from 100 to $300 \mathrm{~Hz}$.

Table 11. Specifications of the coin-type vibration motor and novel linear vibration motor.

\begin{tabular}{|c|c|c|}
\hline Items & Coin-Type Vibration Motor & Linear Vibration Motor \\
\hline Dimension (mm) & $\varnothing 8.0 \times 2.75 \mathrm{t}$ & $\varnothing 8.0 \times 2.50 \mathrm{t}$ \\
\hline Contact type & \multicolumn{2}{|c|}{ Pad type } \\
\hline Rated voltage (V) & 3.0 & 4.35 \\
\hline Resistance (Ohm) & 30.0 & 30.0 \\
\hline Resonance frequency $(\mathrm{Hz})$ & 170 & 280 \\
\hline Input frequency $(\mathrm{Hz})$ & \multicolumn{2}{|c|}{ Around $250 \mathrm{~Hz}$} \\
\hline Acceleration@250 Hz (G) & 0.15 & 0.21 \\
\hline Manufacturing costs & $\$ 0.52$ & $\$ 0.10$ \\
\hline
\end{tabular}

\section{Conclusions}

This research investigated the electromagnetic and mechanical coupling performance of linear vibration motors by using E-M coupling analysis as well as the experimental results. A novel linear vibration motor was developed to reduce the total thickness, reduce the manufacturing cost, and increase the acceleration performance in the working frequency range ( 240 to $260 \mathrm{~Hz}$ ). The proposed linear vibration motor has $9.09 \%$ and $80.77 \%$ reductions in the total thickness and manufacturing cost, respectively. The acceleration at $250 \mathrm{~Hz}$ had a $40.0 \%$ improvement. The design method and analysis method in this study can be used for most linear vibration motor design.

Author Contributions: Conceptualization, Z.-X.J., K.-H.P. and S.-M.H.; methodology, Z.-X.J., K.-H.P. and S.-M.H.; software, Z.-X.J. and K.-H.P.; validation, Z.-X.J. and K.-H.P.; formal analysis, Z.-X.J., K.-H.P. and S.-M.H.; investigation, Z.-X.J. and K.-H.P.; resources, S.-M.H.; data curation, Z-X.J. and K-H.P.; writing-original draft preparation, Z.-X.J.; writing-review and editing, Z.-X.J., K.-H.P. and S.-M.H.; visualization, Z.-X.J.; supervision, S.-M.H.; project administration, S.-M.H. All authors have read and agreed to the published version of the manuscript.

Funding: This research received no external funding.

Conflicts of Interest: The authors declare no conflict of interest.

\section{References}

1. Etter, J.-F. Electronic cigarettes: A survey of users. BMC Public Health 2010, 10, 23. [CrossRef] [PubMed]

2. Hwang, S.-M. Development of Solenoid-Type Vibrators Used for Mobile Phones. IEEE Trans. Magn. 2003, 39, 3262-3264. [CrossRef]

3. Lee, K.B.; Kim, J.H. Horizontal linear vibrating actuator to reduce smart phone thickness. J. Vibroeng. 2013, 15, 2003-2011. 
4. Nam, J.; Yeon, T.; Jang, G. Development of a linear vibration motor with fast response time for mobile phones. Microsyst. Technol. 2014, 20, 1505-1510. [CrossRef]

5. Jiang, Z.-X.; Park, K.H.; Kim, J.-H.; Jiang, Y.-W.; Xu, D.-P.; Hwang, S.M. Analysis and Design of a New Linear Vibration Motor Used to Reduce Magnetic Flux Leakage in In-Vehicle Infotainment. Appl. Sci. 2020, 10, 3370. [CrossRef]

6. Monk, P. Finite Element Methods for Maxwell's Equations; Oxford University Press: Oxford, UK, 2003.

7. Jin, J.M. The Finite Element Method in Electromagnetics; John Wiley \& Sons: Hoboken, NJ, USA, 2015.

8. Hughes, T.J. The Finite Element Method: Linear Static and Dynamic Finite Element Analysis; Courier Corporation: Chelmsford, MA, USA, 2012.

9. Young, W.C.; Budynas, R.G.; Sadegh, A.M. Roark's Formulas for Stress and Strain; McGraw-Hill: New York, NY, USA, 2002.

10. Griffiths, D.J. Introduction to Electrodynamics; Pearson: London, UK, 2005; p. 574.

11. French, A.S.; Torkkeli, P.H.; Squire, L.R. Reference module in neuroscience and biobehavioral psychology. In LR Squire. Encyclopedia of Neuroscience; Academic Press: San Diego, CA, USA, 2009; pp. 689-695.

12. Barlow, S.M.; Custead, R. Vibrography: Single-Interval Up/Down (SIUD) Adaptive Vibrotactile Threshold Estimation of the Glabrous Hand and Perioral Face in Neurotypical Adults. Biomed. J. Sci. Tech. Res. 2019, 22, 16837-16847. [CrossRef]

13. Verrillo, R.T. Vibration sensation in humans. Music Percept. 1992, 9, 281-302. [CrossRef]

Publisher's Note: MDPI stays neutral with regard to jurisdictional claims in published maps and institutional affiliations. 